\title{
Proposta de Roteiro para a Determinação das Variáveis de Soldagem do Processo TIG Pulsado Aplicado à Soldagem de Chapas Finas
}

\author{
(Proposal of Roadmap for Determining the Variables of Pulsed TIG Welding Process Applied to Welding of Thin Plates)
}

\author{
Tiago Vieira da Cunha1 \\ IUFSC, CEM - Centro das Engenharias da Mobilidade, Joinville, Santa Catarina, Brasil, tvc@joinville.ufsc.br
}

\begin{abstract}
Resumo
Na soldagem TIG pulsada a corrente varia entre dois níveis bem definidos de energia numa determinada frequência, sendo, portanto, necessário a regulagem de um conjunto de variáveis composto pela corrente de pulso, tempo de pulso, corrente de base, tempo de base, além da velocidade de soldagem. Entretanto, apesar de ser uma técnica tão amplamente difundida, na prática estas variáveis de soldagem muitas vezes são reguladas de forma arbitrária. Isto pode conduzir ao uso ineficiente da pulsação da corrente quando considerado o resultado final da solda, bem como nos aspectos de produtividade. Diante desta carência, este trabalho tem por objetivo apresentar um roteiro desenvolvido com o intuito de suprir a necessidade prática de se estabelecer critérios para auxiliar a determinação das variáveis da soldagem TIG pulsada, tomando como premissa a largura desejada para o cordão de solda final, a sobreposição entre os pontos de solda que compõem o cordão e a velocidade de soldagem. Por fim, é apresentada uma aplicação deste roteiro na soldagem "bead on plate" de chapas de aço inox com 1,2 mm de espessura.
\end{abstract}

Palavras-chave: Roteiro; Variáveis; TIG Pulsado.

Abstract: In pulsed TIG welding the current varies between two well-defined energy levels in a given frequency being, therefore, necessary to the adjustment of a set of variables consisting of the peak current, peak time, background current, background time and the welding speed. However, despite being a technique so widespread, in practice these welding variables are often regulated arbitrarily. This can lead to inefficient use of the pulsed current regarding the end result of the weld as well as in the aspects of productivity. Given this shortage, this paper aims to present a roadmap developed in order to meet the practical need to establish criteria to assist in the determination of pulsed TIG welding variables, taking as its premise the desired width of the weld bead, overlap between the weld points comprising the weld bead and the welding speed. Finally, one application of this roadmap is presented in welding bead on plate of stainless steel plates with 1.2 mm thickness.

Key-words: Roadmap; Variables; Pulsed TIG.

\section{Introdução}

Os avanços obtidos nas últimas décadas na área de microeletrônica conduziram a uma expansão vertiginosa das soluções baseadas em eletrônica embarcada nas mais diversas áreas da engenharia. Esta tecnologia, aplicada à soldagem a arco, permitiu o desenvolvimento de fontes eletrônicas capazes de realizar o controle mais eficiente das variáveis de soldagem, em especial, o da corrente. Este maior controle, além de propiciar correntes de soldagem com menores erros associados, possibilitou o desenvolvimento de novas técnicas de soldagem, entre elas, a soldagem TIG com corrente pulsada de onda retangular.

Esta variante do processo TIG é caracterizada pela alternância periódica entre níveis altos e baixos (e bem definidos) da cor-

(Recebido em 18/09/2012; Texto final em 03/12/2012). rente de soldagem numa determinada frequência. Conceitualmente, um nível alto de energia é regulado durante os intervalos de alta corrente (pulso), com o intuito de promover a formação de uma poça de fusão, enquanto que nos intervalos de baixa corrente (base), a energia é mantida em níveis baixos, apenas suficientes para garantir que não ocorra a extinção do arco [1], permitindo assim, o resfriamento da poça de fusão [2]. Isto permite que a energia do arco seja utilizada de forma mais eficiente para produzir cordões cujo resultado é uma série de pontos de solda sobrepostos, sendo que a sobreposição entre esses pontos depende da frequência de pulsação da corrente e da velocidade de soldagem [3-5].

De acordo com trabalhos encontrados na literatura [6,7], é na alternância entre níveis altos e baixos de energia que surgem os benefícios do processo de soldagem TIG pulsado. As vantagens relatadas para este método incluem o maior controle sobre as características dimensionais do cordão de solda [8,9], maior tolerância às variações na dissipação de calor [10], menor aporte de calor $[6,11,12]$, redução de tensões residuais e distorções da peça $[11,13]$ e maior controle sobre a poça de fusão [7], princi- 
palmente em posições de soldagem desfavoráveis. Já do ponto de vista metalúrgico, as vantagens relatadas referem-se ao refino de grãos obtido na zona fundida [14], redução da largura da ZAC [15] e controle de segregação [16].

Embora os efeitos metalúrgicos resultantes destas características citadas, possam ser mensuráveis em algumas situações, normalmente em aços termicamente mais sensíveis, o efeito de ordem operacional da solda é o que mais está presente. Devido à periodicidade da redução da corrente de soldagem, a poça de fusão adquire melhores condições de sustentabilidade, propriedade que mais se faz sentir em soldagem fora da posição plana. Isto se reflete fortemente no controle da penetração, seja em passe único para chapas finas, seja para o passe de raiz em chapas mais espessas.

Em corrente pulsada com variáveis bem reguladas pode-se obter mais segurança em relação à penetração, já que a corrente de pulso estará acima da corrente necessária para aquela penetração, mas, atuando durante um tempo tal que a poça de fusão adquira um tamanho que ainda se sustente espacialmente, sem comprometer a qualidade do cordão de solda (poça de fusão dimensionalmente adequada). Após o citado tempo, a corrente é então estabelecida num patamar mais baixo para permitir que a poça de fusão se resfrie. Devido a esta característica, a corrente pulsada é, portanto, indicada como uma técnica indispensável para a soldagem de chapas finas.

Apesar de se constituir numa técnica amplamente difundida, na prática, o conjunto de parâmetros empregado na soldagem TIG pulsada muitas vezes é definido de forma arbitrária, sem que haja critérios que norteie a regulagem das variáveis, bem como um adequado correlacionamento entre as mesmas. Isto pode levar ao uso ineficiente da pulsação da corrente no que diz respeito à obtenção de uma poça de fusão dimensionalmente adequada, refletindo assim, nas características dimensionais do cordão de solda, bem como na produtividade ao ser considerado a velocidade de soldagem. Neste contexto, embora seja possível encontrar na literatura produzida nas últimas décadas trabalhos [2,17-23] cuja abordagem está na influência das variáveis de soldagem sobre as características do cordão de solda, são lim- itados os trabalhos que explorem critérios que auxiliem na determinação concatenada do conjunto de parâmetros da soldagem TIG pulsada. Diante disso, o presente trabalho tem por objetivo apresentar um roteiro cujo intuito é o de suprir a necessidade prática de se estabelecer critérios que auxiliem a determinação das variáveis da soldagem TIG pulsada.

\section{Roteiro}

A abordagem adotada no desenvolvimento do presente roteiro tem seu foco nas características dimensionais dos cordões de solda resultantes. Especificamente na raiz da solda, onde se deseja obter um cordão isento de descontinuidades e com boa regularidade em relação a sua largura, para viabilizar a qualificação do procedimento de soldagem. Deste modo, não se pretende com este trabalho definir valores de frequência de pulsação da corrente que otimize os possíveis efeitos metalúrgicos na poça de fusão, mas, procura-se defini-la de forma concatenada com as demais variáveis da soldagem TIG pulsada, buscando, assim, prover procedimentos de soldagem mais eficientes, capazes de realizar soldas com elevado grau de repetitividade.

\subsection{Determinação do Tempo de Pulso e do Tempo de Base}

No processo TIG pulsado, o efeito da velocidade de soldagem deve ser considerado, pois a uma dada frequência de pulsação da corrente, uma velocidade de soldagem relativamente baixa resultará numa sobreposição muito grande entre os pontos de solda, gerando um aporte de calor excessivo, suficiente para que a poça de fusão escorra. Do contrário, uma velocidade de soldagem muito alta resultará em pontos de solda sem qualquer sobreposição, apresentando falta de continuidade do cordão. Estas considerações evidenciam a importância da velocidade de soldagem e da sobreposição entre os pontos de solda na determinação da frequência de pulsação da corrente ou do período de pulsação. Desta forma, foi desenvolvido um equacionamento matemático com o intuito de determinar os tempos de pulso e de base da corrente de soldagem a partir do diâmetro dos pontos de

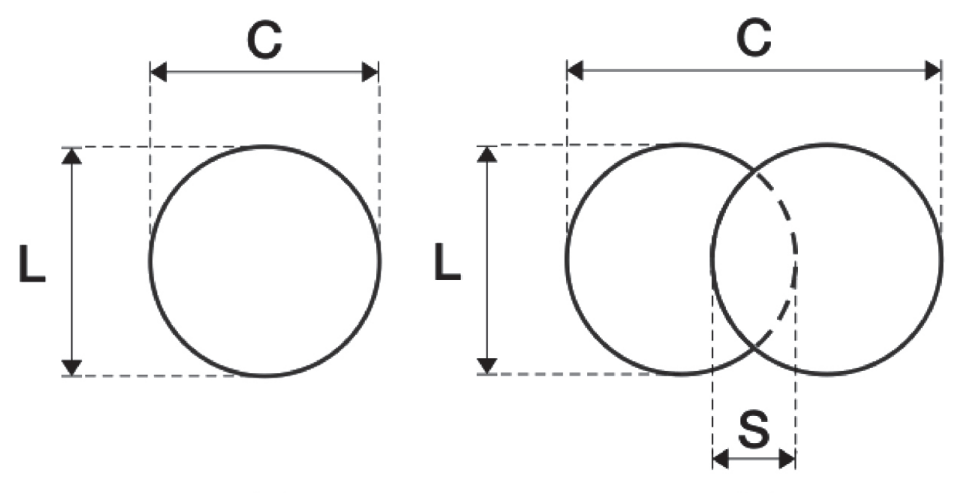

(a)

(b)

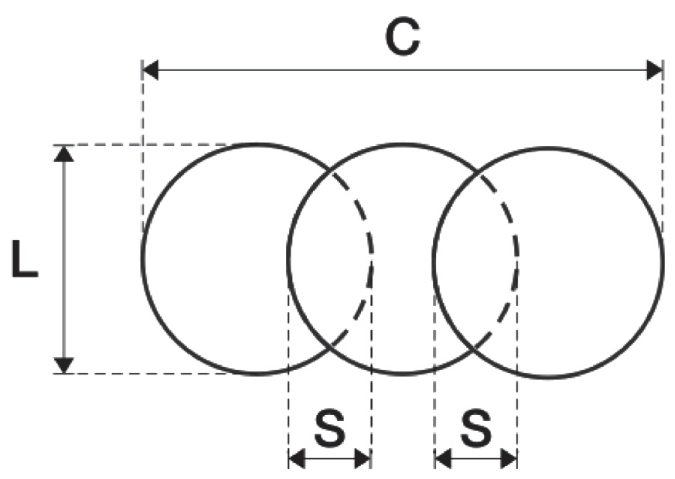

(c)

Figura 1. Representação esquemática de cordões de solda realizados na soldagem TIG pulsada. Em (a) cordão composto por um ponto, em (b) por dois pontos e em (c) por três pontos de solda. 
solda que compõe o cordão, da sobreposição entre estes pontos e da velocidade de soldagem. Neste equacionamento, a velocidade de soldagem durante o período de pulso da corrente foi considerado como sendo igual a zero, com isso, espera-se obter, teoricamente, poças de fusão (pontos de solda) com geometria circular, permitindo assim, a simplificação das equações no desenvolvimento matemático. Caso contrário, o esperado seriam poças de fusão com geometria elíptica, sendo à distância entre seus focos definida pelo produto entre a velocidade de soldagem e o tempo de pulso da corrente.

Na Figura 1a, têm-se representado um cordão com um único ponto de solda, logo, realizado com apenas um período de pulsação da corrente, lembrando que a condição para que isso ocorra é de que a corrente de base seja suficientemente baixa apenas para manter o arco aberto. Neste caso, tem-se que, o comprimento $(\mathrm{C})$ do cordão é igual à sua largura (L).

Na Figura 1b, têm-se um cordão com dois pontos de solda, sendo que a sobreposição entre eles é dada por S. Neste caso, o comprimento do cordão pode ser escrito conforme a Equação 1. De forma análoga, para um cordão composto por três pontos de solda (Figura 1c), têm-se duas sobreposições e, do mesmo modo, o comprimento do cordão pode ser escrito conforme a Equação 2.

$\mathrm{C}=\mathrm{L}+(\mathrm{L}-\mathrm{S})$

$\mathrm{C}=\mathrm{L}+(\mathrm{L}-\mathrm{S})+(\mathrm{L}-\mathrm{S})$

Analisando as Equações 1 e 2, conclui-se que a cada novo período de pulsação da corrente, o termo $(\mathrm{L}-\mathrm{S})$ é adicionado à equação do comprimento do cordão. Desta forma, para n períodos de pulsação da corrente, o comprimento do cordão pode ser escrito conforme a Equação 3.

$\mathrm{C}_{\mathrm{n}}=\mathrm{L}+(\mathrm{n}-1)(\mathrm{L}-\mathrm{S})$

$\mathrm{Na}$ soldagem pulsada, o tempo gasto na execução de um cordão de solda pode ser definido pelo produto entre o período de pulsação da corrente (T) e o número de vezes (n) em que este se repete. Isto, aliado ao fato de que a velocidade de soldagem (V) pode ser definida pela razão entre o comprimento do cordão e o tempo gasto na sua execução, conduz a Equação 4.

$T=\frac{\mathrm{C}_{\mathrm{n}}}{\mathrm{nV}}$

Substituindo-se a Equação 3 na Equação 4 e realizando as devidas simplificações matemáticas, têm-se a Equação 5.

$$
T=\frac{1}{\mathrm{~V}}\left(\mathrm{~L}-\mathrm{S}\left(1-\frac{1}{\mathrm{n}}\right)\right)
$$

Nesta Equação, no limite em que n cresce, ou seja, em termos práticos quando o comprimento do cordão aumenta, o termo (1 - 1/n) tende a um. Desta forma, a Equação 5 pode ser reescrita conforme a Equação 6.

$T=\frac{\mathrm{L}-\mathrm{S}}{\mathrm{V}}$
A proposta deste roteiro prevê a utilização de razão cíclica de $50 \%$. Deste modo, o tempo de pulso (tp) e tempo de base (tb) podem ser definidos conforme a Equação 7, em função do diâmetro (L) dos pontos de solda que compõe o cordão, da sobreposição $(\mathrm{S})$ entre estes pontos e da velocidade de soldagem (V).

$$
t p=t b=\frac{T}{2}=\frac{\left(\frac{\mathrm{L}-\mathrm{S}}{\mathrm{V}}\right)}{2}
$$

\subsection{Determinação da Corrente de Base}

Considerando que, conceitualmente, na soldagem TIG pulsada a fusão da peça ocorre exclusivamente durante os períodos de pulso da corrente, o valor da corrente de base deve ser mantido em níveis apenas suficientes para garantir que não ocorra a extinção do arco, e assim, tornar o seu efeito térmico o menos significativo possível, a fim de tornar, nesta fase, o processo de solidificação da poça de fusão o mais eficiente possível.

Baseado nesta premissa, o presente roteiro indica o emprego de uma corrente de base com um valor mínimo necessário para garantir a estabilidade do arco. Este valor de corrente pode ser definido experimentalmente, utilizando como critério a condição visual de estabilidade do arco. Para tanto, basta realizar soldas em corrente contínua para as condições operacionais de soldagem no qual será aplicada a corrente pulsada (diâmetro do eletrodo, ângulo de afiação, material de base, distância eletrodo peça e vazão do gás de proteção), reduzindo gradativamente a corrente até o limite em que o arco se apresente deficiente quanto a sua estabilidade. $\mathrm{O}$ valor da corrente de base a ser utilizado deve ser ligeiramente maior (cerca de $5 \mathrm{~A}$ ) à encontrada nesta condição.

\subsection{Determinação da Corrente de Pulso}

Uma vez definidos os tempos de pulsação da corrente e a corrente de base, a próxima etapa deste roteiro consiste na determinação da corrente de pulso. Para tanto, realiza-se, inicialmente, o menor cordão de solda capaz de ser realizado na soldagem TIG pulsada, ou seja, um único ponto de solda, conforme esquematizado na Figura 1a. Para a execução deste ponto de solda é necessário o emprego de uma corrente atuando durante um tempo igual ao tempo de pulso já determinado, que resulte numa largura do ponto na face oposta da chapa, o que será denominado como raiz, correspondente a largura utilizada no cálculo dos tempos de pulsação da corrente.

No limite em que o tempo de base tende a infinito, teoricamente, a corrente de pulso necessária para a realização do cordão constitui-se na mesma corrente utilizada na realização do ponto de solda descrito anteriormente. Pois, nesta condição, durante a execução sequenciada dos pontos de solda que compõem o cordão, a peça estaria completamente fria a cada novo período de pulso da corrente. No entanto, na medida em que o tempo de base é reduzido, faz-se necessário reduzir proporcionalmente a energia de soldagem durante o período de pulso, a fim de compensar os efeitos térmicos devido ao pré-aquecimento da peça, ocasionado pelos pontos de solda anteriores. Como forma de reduzir esta energia de soldagem, atua-se na amplitude da corrente 
de pulso, tendo em vista que o tempo de pulso já foi definido previamente pela Equação 7 para uma dada condição de soldagem. Para determinar o valor da corrente de pulso a ser empregado durante a soldagem, realizam-se cordões de solda, em corrente pulsada, empregando todas as variáveis previamente definidas (tempo de pulso, corrente de base, tempo de base e velocidade de soldagem) alterando-se unicamente a amplitude da corrente de pulso, com o intuito de fornecer somente a diferença de energia de soldagem necessária para obter cordões compostos por pontos de solda dimensionalmente compatíveis com aquele utilizado no cálculo dos tempos de pulsação da corrente.

\section{Avaliação Experimental}

\subsection{Materiais e Métodos}

Com o propósito de avaliar experimentalmente o roteiro proposto, o mesmo foi aplicado na soldagem "bead on plate" de chapas de aço inox AISI $304(150 \mathrm{~mm}$ x $80 \mathrm{~mm})$ com 1,2 mm de espessura. $\mathrm{Na}$ execução dos ensaios foi utilizado eletrodo de tungstênio toriado (EWTh-2) com diâmetro de 2,4 mm, ângulo de afiação de $30^{\circ}$ e ângulo de ataque de $90^{\circ}$. A distância eletrodo peça (DEP) utilizada foi de $3 \mathrm{~mm}$, ângulo de ataque do eletrodo de $90^{\circ}$ e argônio puro como gás de proteção $(10 \mathrm{~L} / \mathrm{min})$ e gás de purga $(8 \mathrm{~L} / \mathrm{min})$.

Para a medição da largura do cordão na raiz e da sobreposição entre os pontos de solda que o compõe, as amostras foram fotografadas e as medidas realizadas com o auxílio do software de análise de imagens "UTHSCSA Image Tool v3.0". Este software permite a realização de medidas em imagens desde que seja realizada a calibração a partir de uma distância conhecida.

Com o intuito de possibilitar a execução rápida e eficiente do roteiro proposto, foi desenvolvida a bancada de ensaios de soldagem mostrada na Figura 2.

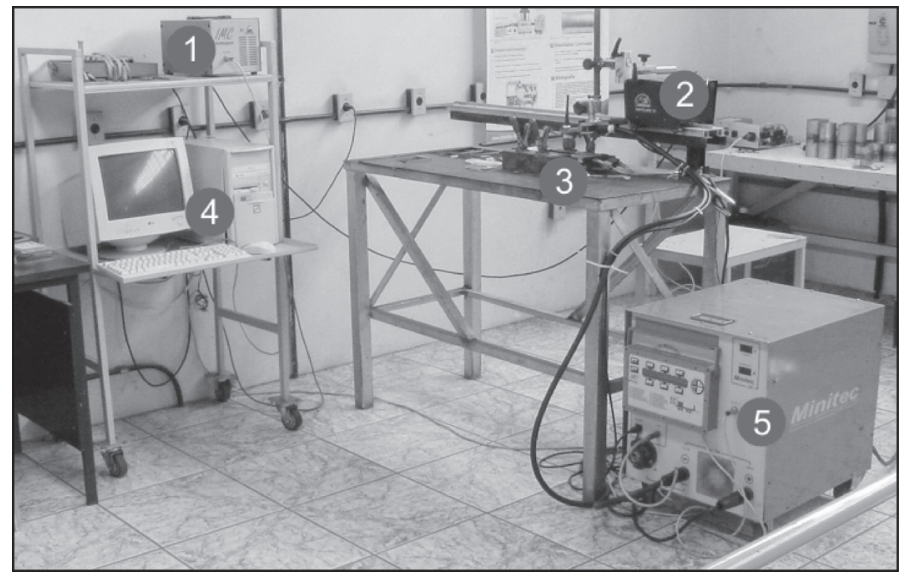

Figura 2. Bancada de ensaios desenvolvida, composta por (1) Unidade de controle e (2) Carro do sistema de deslocamento de tocha, (3) Mesa de soldagem, (4) Computador equipado com uma placa de interface e (5) Fonte de soldagem.

Esta bancada opera de forma totalmente integrada, com um microcomputador, equipado com um software de controle e uma placa de interface, realizando o controle simultâneo do sistema de deslocamento de tocha e da fonte de soldagem. O controle do sistema de deslocamento de tocha é realizado por intermédio de uma comunicação serial padrão RS-232, enquanto que o da fonte de soldagem por uma conexão própria do equipamento, destinada para operações em modo remoto. Este modo de operação permite que a fonte de soldagem seja comandada por qualquer agente externo desde que respeitado o padrão dos sinais.

O software de controle foi desenvolvido utilizando a linguagem de programação Pascal. Neste, foram implementadas três funções principais, caracterizando assim, três modos de operação da bancada: "modo simples", "modo multifases" e "modo normal".

O modo simples executa o procedimento específico para a realização de um único ponto de solda. Neste modo, após a abertura do arco, a tocha de soldagem é deslocada até uma posição predefinida no programa, imprimindo a corrente de base. Ao chegar nesta posição, a corrente é comutada para outro valor de corrente (Iponto) e atua durante um tempo correspondente ao tempo de pulso. Em seguida, o arco é extinto e a tocha de soldagem retorna automaticamente para sua posição de origem, conforme é retratado no gráfico da Figura 3. O modo com o qual este procedimento foi concebido visa realizar o ponto de solda numa condição tal que os efeitos térmicos de preaquecimento da peça, devido à corrente de base, sejam atenuados. Com isso, espera-se obter um bom desempenho da bancada quanto à repetitividade na execução dos ensaios.

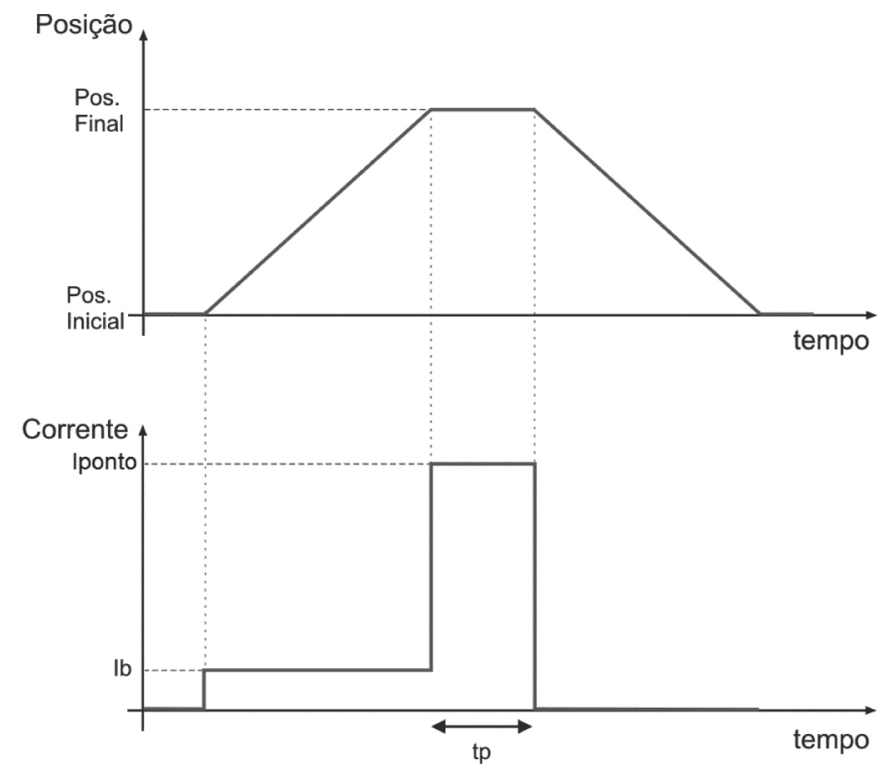

Figura 3. Procedimento de realização do ponto de solda (Modo simples).

Para determinar a corrente de pulso a ser empregada na realização do cordão de solda, foi implementado no software de controle o modo multifases. Neste modo, configura-se individualmente para cada um dos oito estágios disponíveis o valor percentual da corrente de pulso, tendo como base a corrente utilizada na realização do ponto de solda no modo simples, e o tempo de duração (te) de cada estágio. As demais variáveis de soldagem (tempo de pulso, corrente de base, tempo de base e 
velocidade de soldagem) são comuns a todos os estágios. Após a abertura do arco, a soldagem é iniciada com as variáveis do primeiro estágio, transcorrido o tempo do primeiro estágio, a corrente de pulso é alterada automaticamente para a corrente de pulso do segundo estágio, e assim, sucessivamente até que o último estágio seja realizado (Figura 4).

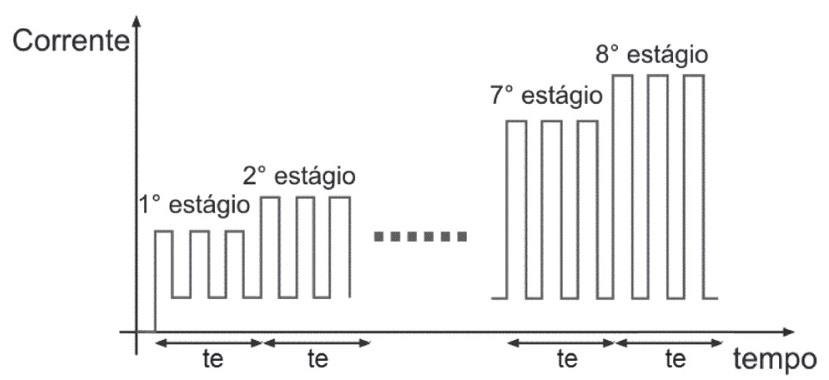

Figura 4. Forma de onda da corrente no modo de operação multifases.

Ainda neste modo de operação, o deslocamento da tocha de soldagem pode ocorrer de forma contínua ou sincronizada com a pulsação da corrente. No modo sincronizado, o sistema de deslocamento de tocha imprime velocidade de soldagem igual a zero nos períodos de pulso, enquanto que nos períodos de base a velocidade é selecionada na tela do programa. O propósito desta função é buscar aproximar as condições práticas de execução das soldas àquelas adotadas no desenvolvimento matemático do roteiro. Este deslocamento sincronizado da tocha de soldagem também está disponível no modo de operação normal da bancada, que por sua vez, é destinado às operações de soldagem onde se deseja realizar um cordão de solda em corrente pulsada.

\subsection{Aplicação do Roteiro}

$\mathrm{Na}$ aplicação do presente roteiro, o propósito foi o de obter um conjunto de parâmetros que promova uma solução consistente quanto à continuidade e uniformidade da raiz da solda. Deste modo, elegeu-se como objetivo a obtenção de uma raiz composta por pontos de solda com largura de $2,0 \mathrm{~mm}$, sobreposição entre estes pontos de $50 \%$, ou seja, $1 \mathrm{~mm}$ e velocidade de soldagem de $1,25 \mathrm{~mm} / \mathrm{s}(7,5 \mathrm{~cm} / \mathrm{min})$.

Primeiramente calculou-se os tempos de pulsação da corrente fazendo-se uso da Equação 7. Como resultado, obtiveramse tempos de pulso e de base iguais a $0,4 \mathrm{~s}$, conforme mostra a Equação 8 .

$t p=t b=\frac{\left(\frac{2,0-1,0}{1,25}\right)}{2}=0,4 \mathrm{~s}$

O valor da corrente de base foi definido experimentalmente. Para tanto, foram realizados ensaios em corrente contínua nas mesmas condições operacionais de soldagem no qual será aplicada a corrente pulsada, conforme descrito no roteiro. Nestes ensaios, foi empregada, inclusive, a mesma fonte de energia. Como resultado, foi estabelecido o valor da corrente de base em
$10 \mathrm{~A}$, por se caracterizar num valor mínimo necessário para garantir a estabilidade do arco.

Em seguida, utilizado o modo de operação simples da bancada, foram realizados pontos de solda buscando identificar um valor de corrente que, atuando durante um tempo igual ao tempo de pulso $(0,4 \mathrm{~s})$, resultasse num ponto de solda cuja largura na raiz fosse cerca de 2,0 $\mathrm{mm}$. Como resultado, obteve-se um ponto de solda com largura média na raiz de 2,4 mm (medido) para uma corrente de 130 A (Figura 5).

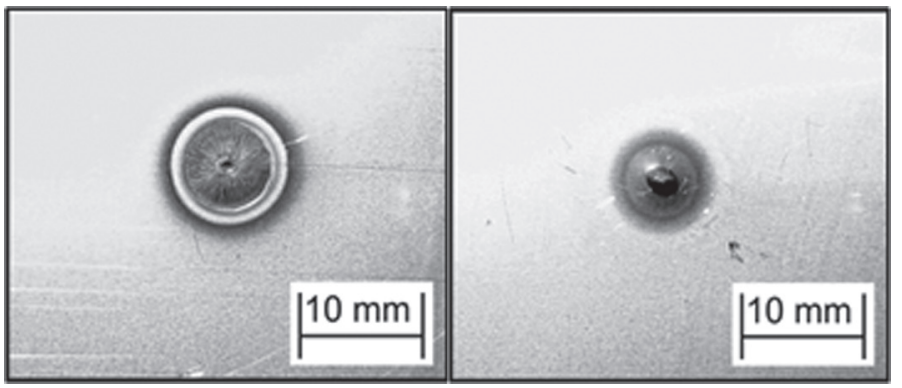

Figura 5. (a) Face e (b) raiz do ponto de solda realizado com corrente de 130 A e tempo de duração de 0,4 s.

Na sequência, foram realizados ensaios para a determinação da corrente de pulso a ser empregada na execução do cordão de solda. Nestes ensaios, foi utilizado o modo de operação multifases da bancada. Para cada estágio, foi regulado um valor percentual para a corrente de pulso de acordo com a corrente utilizada na realização do ponto de solda (130A). Na Tabela 1 é apresentado o conjunto de parâmetros utilizados em cada estágio de solda.

Tabela 1. Variáveis utilizadas na determinação da corrente de pulso no modo multifases.

\begin{tabular}{|c|c|c|c|c|c|c|c|c|c|}
\hline \multicolumn{10}{|c|}{ Variáveis de soldagem } \\
\hline Estágio & $1^{\circ}$ & $2^{\circ}$ & $3^{\circ}$ & $4^{\circ}$ & $5^{\circ}$ & $6^{\circ}$ & $7^{\circ}$ & $8^{\circ}$ & \\
\hline \multirow{2}{*}{$\mathrm{Ip}$} & 10 & 20 & 30 & 40 & 50 & 60 & 70 & 80 & $(\%)$ \\
\cline { 2 - 10 } & 13 & 26 & 39 & 52 & 65 & 78 & 91 & 104 & $(\mathrm{~A})$ \\
\hline te $^{*}$ & 10 & 10 & 10 & 10 & 10 & 10 & 10 & 10 & $(\mathrm{~s})$ \\
\hline tp & \multicolumn{10}{|c|}{0,4} & $(\mathrm{~s})$ \\
\hline $\mathrm{Ib}$ & \multicolumn{10}{|c|}{0,4} & $(\mathrm{~A})$ \\
\hline tb & \multicolumn{10}{|c|}{0} & $(\mathrm{~s})$ \\
\hline $\mathrm{Vb}$ & \multicolumn{10}{|c|}{$\mathrm{cm} / \mathrm{min})$} \\
\hline $\mathrm{Vp}$ & \multicolumn{10}{|c}{} & $(\mathrm{mm} / \mathrm{s})$ \\
\hline
\end{tabular}

Nota: te representa o tempo de duração do estágio.

Com o intuito de aproximar as condições práticas de execução destas soldas àquelas adotadas no desenvolvimento do roteiro, foi utilizada, nestes ensaios, velocidade de soldagem sincronizada com a pulsação da corrente. Deste modo, foi empregada velocidade durante o período de pulso $(\mathrm{Vp})$ igual a zero e durante o período de base $(\mathrm{Vb})$ igual ao valor que culminasse na velocidade média de soldagem de $1,25 \mathrm{~mm} / \mathrm{s}(7,5 \mathrm{~cm} / \mathrm{min})$. Com isso, espera-se obter poças de fusão (pontos de solda) cuja forma se aproxime de uma geometria circular e, assim, possi- 
bilite uma melhor avaliação dos resultados. O cordão resultante deste ensaio pode ser visualizado na Figura 6, onde cada estágio está indicado com o respectivo valor percentual da corrente de pulso utilizado.

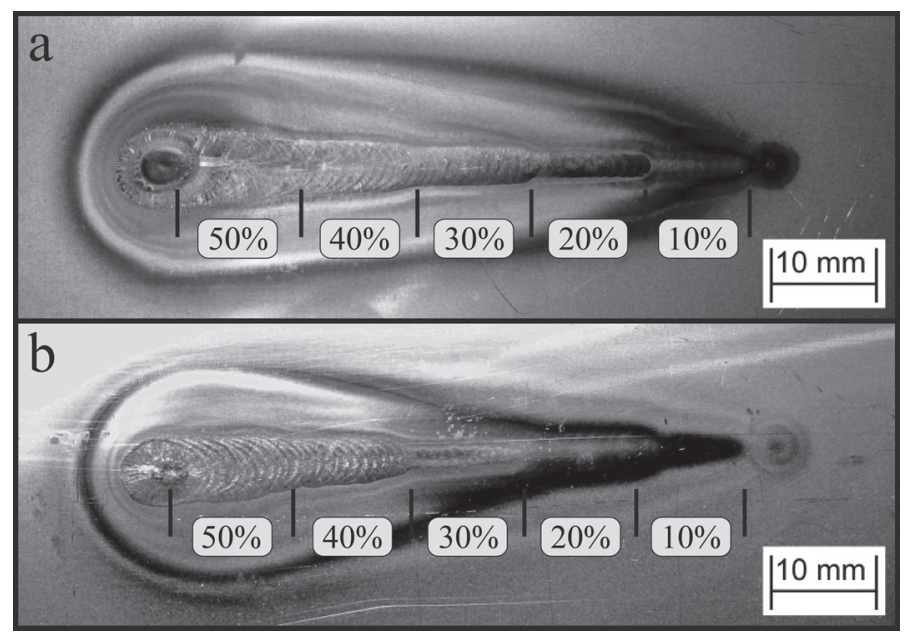

Figura 6. (a) Face e (b) raiz da solda realizada para a determinação da corrente de pulso.

Como se pode observar, para uma corrente de pulso igual a $50 \%$ do valor de corrente utilizado para a realização do ponto de solda (65 A), o cordão apresentou uma largura, tanto na face como na raiz, extremamente elevada devido ao excesso de energia de soldagem. Neste caso, o ensaio foi interrompido antes que se completassem os oito estágios para evitar a perfuração da chapa. Entretanto, para uma corrente de pulso de 30\%, obteve-se uma largura na raiz da solda próxima de 2,0 $\mathrm{mm}$. Diante disso, a fim de refinar o resultado obtido, novos ensaios foram realizados, nas mesmas condições do ensaio anterior, porém, com incrementos de $1 \%$ na amplitude da corrente de pulso para a faixa compreendida entre $26 \%$ e $33 \%$ (Figura 7 ).

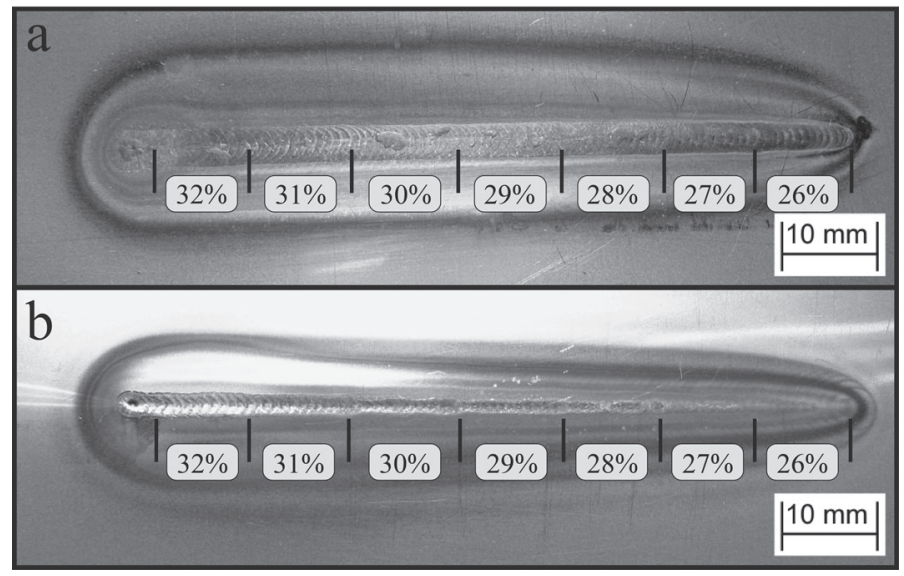

Figura 7. (a) Face e (b) raiz da solda realizada para a determinação da corrente de pulso.

Analisando a raiz da solda, percebe-se que para uma corrente de pulso igual a $31 \%$ (40 A), obteve-se uma condição de soldagem com pontos de solda dimensionalmente compatíveis com o ponto realizado anteriormente com corrente de 130 A. Já para menores valores de corrente de pulso, além de incompatível do ponto de vista dimensional, a largura da raiz da solda não foi uniforme, enquanto que, para uma maior corrente de pulso obteve se excesso na largura. Desta forma, definida a corrente de pulso, obteve-se determinado por completo todo o conjunto de parâmetros para a soldagem TIG pulsada.

A partir dos parâmetros obtidos com a aplicação do presente roteiro, foram realizados cordões de solda (Figura 8) nas mesmas condições em que foi aplicado o roteiro, com o intuito de mensurar os resultados obtidos no que diz respeito às características dimensionais do cordão.

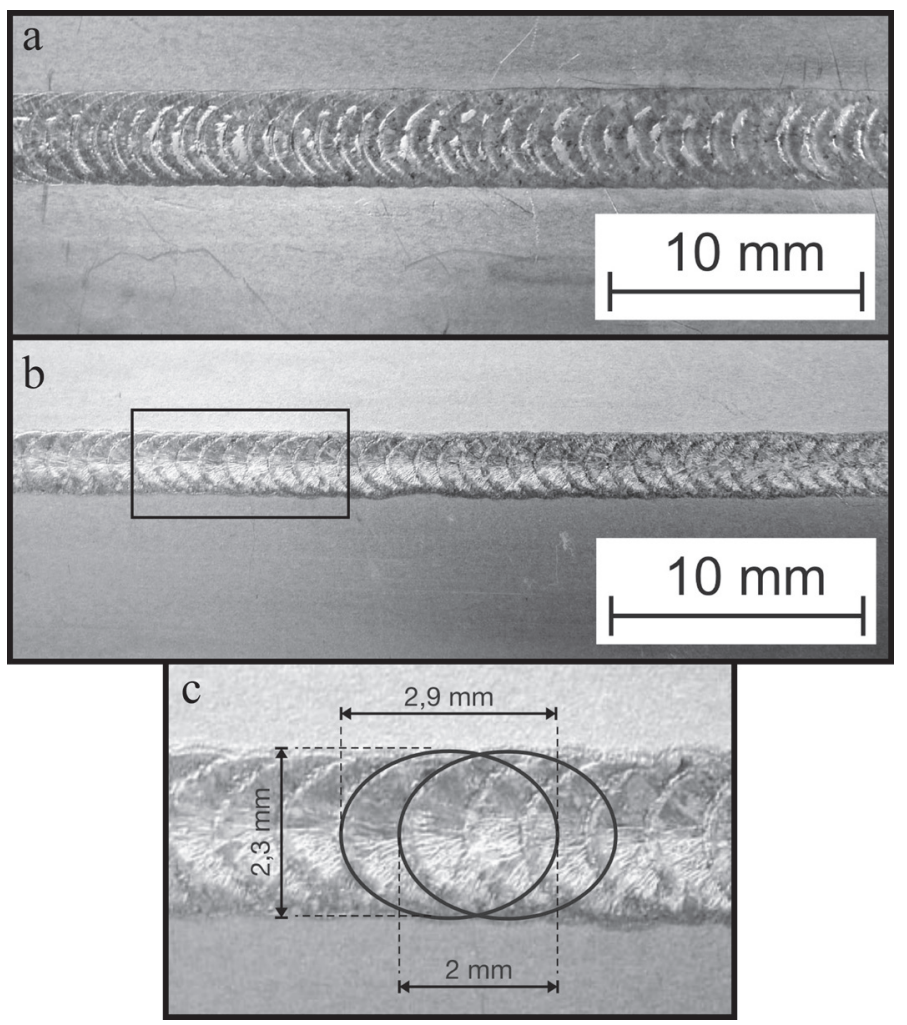

Figura 8. (a) Face, (b) raiz e (c) detalhe da raiz da solda realizada com os parâmetros resultantes da aplicação do roteiro. Ip: $40 \mathrm{~A}$, tp: 0,4 s, Ib: $10 \mathrm{~A}, \mathrm{tb}: 0,4 \mathrm{~s}, \mathrm{Vp}: 0 \mathrm{~mm} / \mathrm{s}$ e Vb: $2,5 \mathrm{~mm} / \mathrm{s}(15,0$ $\mathrm{cm} / \mathrm{min})$.

Conforme pode ser observado, os cordões de solda realizados com os parâmetros obtidos a partir da aplicação do presente roteiro apresentaram, tanto na face quanto na raiz, um bom aspecto visual. A largura média obtida na raiz foi de $2,3 \mathrm{~mm}$, valor tido como aceitável, considerando que o objetivo inicial foi o de obter cordões com largura de 2,0 mm. Além disso, os parâmetros de soldagem empregados resultaram numa raiz com boa uniformidade, o que se traduz em segurança quando a exigência é a continuidade do cordão, requesito imprescindível para a qualificação do procedimento de soldagem.

Outro aspecto a ser avaliado diz respeito à sobreposição entre os pontos de solda que compõe o cordão. Conforme pode ser visto, apesar do deslocamento da tocha ocorrer de forma sincronizada com a pulsação da corrente, o procedimento de soldagem resultou em cordões compostos por pontos de solda 
com geometria elíptica. Acredita-se que isto se deve ao resfriamento desigual da poça de fusão na direção longitudinal do cordão durante o período de atuação da corrente de base, pois a cada novo período de pulso da corrente, um novo ponto de solda é realizado com uma parcela sobreposta ao cordão de solda recém-solidificado e, portanto, a uma temperatura superior àquela região onde se encontra a outra parte do ponto que não houve sobreposição. Com esta deformação dos pontos de solda, a sobreposição média medida entre os mesmos foi em torno de 2 $\mathrm{mm}$. Isto representa uma sobreposição real de aproximadamente $69 \%$, porém, se for desconsiderada a excentricidade dos pontos no cálculo da sobreposição, ou seja, pontos circulares com diâmetro de 2,3 mm, este valor cai para cerca de $60 \%(1,4 \mathrm{~mm})$. Acredita-se que esta divergência entre a sobreposição obtida e a definida na aplicação do roteiro, se deve ao erro na velocidade média de soldagem. Este erro estaria associado à dinâmica de resposta do sistema de deslocamento de tocha na transição entre as velocidades impostas durante os períodos de pulso (Vp) e de base $(\mathrm{Vb})$. Este erro não pode ser mensurado durante a realização do presente trabalho.

\section{Conclusões}

Neste trabalho foi apresentada uma proposta de roteiro com o intuito de auxiliar a determinação das variáveis do processo de soldagem TIG pulsado aplicado à soldagem de chapas finas, tendo como foco as características dimensionais da raiz do cordão de solda.

A partir dos resultados obtidos por meio da aplicação do presente roteiro para uma dada condição de soldagem, conclui-se que os objetivos almejados foram alcançados. Conforme se pode verificar, com o emprego das variáveis fornecidas pelo roteiro, foram obtidos cordões de solda consistentes quanto à sua uniformidade e, principalmente, continuidade da raiz. Quanto aos aspectos dimensionais relativos à largura da raiz e à sobreposição entre os pontos de solda que compõem o cordão, estes foram compatíveis com o pretendido, sendo as diferenças encontradas atribuídas aos efeitos térmicos inerentes do processo de soldagem e das características dos equipamentos utilizados.

Contudo, apesar dos resultados obtidos, percebe-se a necessidade de refinamento e evolução deste roteiro, no sentido de aperfeiçoa-lo e, ao mesmo tempo, expandir o seu campo de aplicação para outras condições de soldagem.

\section{Agradecimentos}

O autor agradece à ANP - Agência Nacional de Petróleo, ao MECPETRO - Programa De Recursos Humanos em Engenharia Mecânica para Petróleo e Gás e ao POSMEC - Programa de Pós Graduação em Engenharia Mecânica da UFSC.

\section{Referências Bibliográficas}

[1] MADALI, F.; SHAMANIAN, M.; ASHRAFIZADEH, F. Effect of pulse current on microstructure and wear resistance of Stellite6/tungsten carbide claddings produced by tungsten inert gas process. Surface \& Coatings Technology, 2011.
[2] TSANG, K. H.; SUNG, H. L. Evaluation study on angular distortion and residual stress of stainless steel pulsed TIG weldments. Advanced Materials Research, 291-294, 2011.

[3] KUMAR, T. S.; BALASUBRAMANIAN, V.; SANAVULLAH, M. Y. Influences of pulsed current tungsten inert gas welding parameters on the tensile properties of AA 6061 aluminium alloy. Materials and Design, 28, 2007.

[4] CUNHA, T. V. Desenvolvimento de equipamento e de metodologia de parametrização para a soldagem orbital TIG. Florianópolis: Dissertação de mestrado. Dept. de Eng. Mecânica, UFSC, Out. 2008.

[5] BALASUBRAMANIAN, V.; RAVISANKAR, V. Effect of pulsed current welding on mechanical properties of high strength aluminum alloy. Int J Adv Manuf Technol, 2008.

[6] STREET, J. A. Pulsed arc welding. 1 ${ }^{\text {a }}$. ed. [S.1.]: Abington publishing, 1990.

[7] AWS. Welding Handbook. 8a Ed. ed. [S.1.]: AWS, v. 2, 1991. [8] TSENG, K. H.; CHOU, C. P. Effect of pulsed gas tungsten arc welding on angular distortion in austenitic stainless steel weldments. Science and Technology of Welding and Joining, 6, 2001.

[9] TSENG, K. H.; CHOU, C. P. The effect of pulsed GTA welding on the residual stress of a stainless steel weldment. Journal of material processing technology, 123, 2002.

[10] SIMPSON, R. P. Controlled weld-pool solidification structure and resultant properties with yttrium inoculation of Ti--6Al-6V--2Sn welds. Welding Journal, 56, n. 3, 1977.

[11] LEITNER, R. E.; MCELHINNEY, G. H.; PRUITT, E. L. An investigation of pulsed GTA welding variables. Welding Journal, 52, n. 9, 1973.

[12] BALASUBRAMANIAN, M.; JAYABALAN, V.; BALASUBRAMANIAN, V. Developing mathematical models to predict tensile properties of pulsed current gas tungsten arc welded Ti-6Al-4V alloy. Materials and Design, 2008.

[13] SURESH, M. V. et al. Effect of pulse frequency in gas tungsten arc welding of powder metallurgical preforms. Science and Technology of Welding and Joining, 9, n. 4, 2004.

[14] WU, C. S.; ZHENG, W.; WU, L. Modelling the transient behaviour of pulsed current tungsten-inert-gas weldpools. Modelling Simul. Mater. Sci. Eng., 7, 1998.

[15] JANAKI, R. G. D.; MITRA, T. K.; SHANKAR, V. Microstructural refinement through inoculation of Type $7020 \mathrm{Al}-$ $\mathrm{Zn}-\mathrm{Mg}$ alloy welds and its e $\square$ ect on hot cracking and tensile property. J Mater Process Technol, 142, 2003.

[16] BABU, N. K.; RAMAN, G. S. S. Influence of current pulsing on microstructure and mechanical properties of Ti-6Al-4V TIG weldments. Science and Technology of Welding and Joining, 11, n. 4, 2006.

[17] GUIMARÃES, A. S.; ALMEIDA NETO, J. C. P. Efeitos dos parâmetros de pulso sobre a geometria do cordão de solda em soldagem de chapa fina de aço inox AISI 304 pelo processo TIG pulsado. Soldagem \& Inspeção, 6, 1998.

[18] GONZALEZ, A. R.; CASSINA, J. C.; MACHADO, I. G. Técnicas fatoriais na avaliação da influência dos parâmetros do pulso sobre a geometria do cordão em soldagem por processo TIG com corrente pulsada. Caxias do Sul - RS: XXI ENTS. 1995. 
[19] GONZALEZ, A. R.; CASSINA, J. C.; MACHADO, I. G. TIG Convencional e Pulsado: Efeito da Corrente e Velocidade de Soldagem sobre a Geometria do Cordão de Solda em Aço AISI 304. Contagem - MG: XX ENTS. 1994.

[20] JORGE, J. C. F.; ET AL. Estudo da variação dos parâmetros de soldagem do processo TIG pulsado nas características do cordão de solda. Guarujá - SP: XIII ENTS. 1987.

[21] TRAIDIA, A.; ROGER, F.; GUYOT, E. Optimal parameters for pulsed gas tungsten arc welding in partially and fully penetraded weld pools. International Journal of Thermal Sciences, v. 49, 2010.

[22] LOTHONGKUM, G.; VIYANIT, E.; BHANDHUBANYOUNG, P. Study on the effects of pulsed TIG welding parameters on delta-ferrite content, shape factor and bead quality in orbital welding of AISI 316L stainless steel plate. Journal of Materials Processing Technology, v. 110, 2001.

[23] AESH, A. M. Optimization of weld bead dimensions in GTAW of aluminum-magnesium alloy. Materials and Manufacturing Processes, v. 16, n. 5, 2001. 